\title{
Lead-free Solder Joint Reliability - State of the Art and Perspectives
}

\author{
Jianbiao Pan, Ph.D. \\ Cal Poly State University \\ San Luis Obispo, CA 93407 \\ Phone: (805) 756-2540 \\ Fax: (805) 756-1420 \\ Email: pan@calpoly.edu
}

\author{
Jyhwen Wang, Ph.D. \\ Texas A\&M University \\ College Station, TX 77843 \\ Phone: (979) 845-4903 \\ Fax: (979) 862-7969 \\ Email: jwang@tamu.edu
}

\author{
David M. Shaddock \\ GE Global Research Center, \\ Niskayuna, NY 12309 \\ Phone: (518) 387-4051 \\ Fax: (518) 387-5442 \\ shaddock@research.ge.com
}

\begin{abstract}
There is an increasing demand in replacing tin-lead $(\mathrm{Sn} / \mathrm{Pb})$ solders with lead-free solders in the electronics industry due to health and environmental concern. The European Union recently passed a law to ban the use of lead in electronic products. The ban will go into effect in July of 2006. The Japanese electronics industry has worked to eliminate lead from consumer electronic products for several years. Although currently there are no specific regulations banning lead in electronics devices in the United States, many companies and consortiums are working on lead-free solder initiatives including Intel, Motorola, Agilent Technologies, General Electric, Boeing, NEMI and many others to avoid a commercial disadvantage.

The solder joints reliability not only depends on the solder joint alloys, but also on the component metallization and PCB metallization. Reflow profile has significant impact on lead-free solder joint performance also because it influences wetting and microstructure of the solder joint. Majority researchers use temperature cycling for accelerated reliability testing since the solder joint failure mainly comes from thermal stress due to CTE mismatch. A solder joint failure could be caused by crack initiation and growth or by macroscopic solder facture. There are conflicting views of the reliability comparison between lead-free solders and tin-lead solders.

This paper first reviews lead-free solder alloys, lead-free component finishes, and lead-free PCB surface finishes. Tin whisker issue is also discussed. Then the lead-free solder joint testing methods are presented; finite element modeling of lead-free solder joint reliability is reviewed; and experimental data comparing lead-free and tin-lead solder joint reliability are summarized. Finally the paper gives perspectives of transitions to a totally leadfree manufacturing.
\end{abstract}

Keywords: Lead free solder, reliability, review

\section{Introduction}

There is an increasing demand in replacing tin-lead $(\mathrm{Sn} / \mathrm{Pb})$ solders with lead-free solders in the electronics industry due to health and environmental concern. Traditional eutectic tin-lead solder (Sn63/Pb37) has been used in electronics industry exclusively because of its low cost, excellent physical and chemical properties, and robust reliability. However, electronic products are normally disposed in landfill, from which lead will contaminate underground water and endanger humans. The shorter life cycle of today's consumer electronics increases the environmental impact significantly.

The European Union (EU) passed a law to ban the use of lead in electronics on February 13, 2003. The ban goes into effect on July 1, 2006. The Japanese electronics industry has worked to eliminate lead from consumer electronic products for several years. Although currently there are no specific regulations banning lead in electronics devices in the United States, many companies are working on leadfree solder initiatives including Intel [1], Motorola [2], Agilent Technologies [3], General Electric, Boeing [4], and many others to avoid a commercial disadvantage.

To comply with environmental regulations and avoid marketing disadvantage, many consortium have been formed to conduct research on lead-free solders and lead-free solder joint reliability, for example, National Electronics Manufacturing Initiative (NEMI) [5], National Center for Manufacturing Sciences (NCMS) [6], High Density Packaging Users Group (HDPUG) [7], Massachusetts Toxics Use Reduction Institute (TURI) [8], Joint Group on Pollution Prevention (JGPP) [9], Computer Aided Life Cycle Engineering (CALCE) in the University of Maryland [10], Tin Technology [11], and EU consortium known as IDEALS (Improved 
Design Life and Environmentally Aware Manufacturing of Electronic Assemblies by LeadFree Soldering). Many technical societies are active in organizing activities related to lead-free soldering. These societies include IPC [12], Surface Mount Technology Association (SMTA), International Microelectronics and Packaging Society (IMAPS), and IEEE/CPMT.

This paper first reviews lead-free solder alloys, lead-free component finishes, and lead-free Printed Circuit Board (PCB) surface finishes. Tin whisker issue is also discussed. Then the lead-free solder joint testing methods are presented; finite element modeling of lead-free solder joint reliability is reviewed; and experimental data comparing leadfree and tin-lead solder joint reliability are summarized. Finally the paper gives perspectives of transitions to a totally lead-free manufacturing.

\section{Lead-Free Solder Alloys}

The lead-free solder is generally defined as the lead $(\mathrm{Pb})$ level in solder less than $0.1 \%$ by weigh, though there is no standard lead-free definition yet [13]. The definition is adopted by Japanese Electronic Industry Development Association (JEIDA) and European Union End of Life Vehicles Directives (EUELVD), and met ASTM B32-96 and ISO 9453 specifications. But the Joint Electronic Device Engineering Council (JEDEC) in the United States recommends lead-free as less than $0.2 \%$ lead by weight. The JEDEC's definition meets ANSI/JSTD-006 specifications.

In the last 10 years, many lead-free solders have been proposed and much research and testing has been done on lead-free solder materials. For example, NCMS recommended SnAg3.5, SnAg3.5Bi4.8, and BiSn42. Note that SnAg3.5Bi4.8 means 3.5 percent in weight Ag, and 4.8 percent in weight $\mathrm{Bi}$, with the leading element $\mathrm{Sn}$ making up the balance to $100 \%$. NEMI recommended SnAg3.9Cu0.6 for reflow soldering and SnCu0.7 for wave soldering. Major Japanese electronics manufacturers investigated many lead-free solders including SnAg3.5 and SnAg3.0Cu0.5. A database of solder properties with emphasis on new lead-free solders was developed with the support of National Institute of Standards and Technology (NIST) and Colorado School of Mines [14].

Among many developed lead-free solders, tin-silver-copper (SnAgCu or SAC) appears the best choice as an alternative to $\mathrm{Sn} / \mathrm{Pb}$ solder for most applications. There are several variations of the SnAgCu alloy. The NEMI in the United States recommends SnAg3.9Cu0.6 for reflow soldering application [15]. The European consortium BRITE-EURAM focused its research and development efforts on SnAg3.8Cu0.7. The standard lead-free solder alloy in Japan is SnAg3Cu0.5 [16], which was recommended by Japan Electronics and Information Technology Industry (JEITA).

There are several major differences between $\mathrm{SnPb}$ and $\mathrm{SnAgCu}$ lead-free solders. First, $\mathrm{SnAgCu}$ solders require higher reflow temperatures than $\mathrm{SnPb}$. The melting point of $\mathrm{SnAg3.8Cu0.7}$ is $219^{\circ} \mathrm{C}$, and that of $\mathrm{SnAg} 3 \mathrm{Cu} 0.5$ is $217^{\circ} \mathrm{C}$. All are higher than eutectic $\mathrm{SnPb}$ solder, which has the melting point of $183^{\circ} \mathrm{C}$. Second, the wetting of $\mathrm{SnAgCu}$ solders is generally not as good as SnPb alloy [17], although improvement in spreading was observed in lead-free solder when a nitrogen atmosphere was used [18]. Third, SnAgCu solder joints have more voids than $\mathrm{SnPb}$. More voiding was observed when $\mathrm{SnAgCu}$ alloy was assembled with $\mathrm{SnPb}$ component finishes $[19,61]$. Fourth, the appearance between SnAgCu and $\mathrm{SnPb}$ is different. $\mathrm{SnPb}$ solder joints look shiny and SnAgCu look dull. This difference requires new visual inspection specifications for lead-free solder joints.

\section{Lead-Free Component Finishes}

A component lead finish that has compatibility with solder assembly processes and product life environments has historically been a well defined choice, SnPb. However, the advent of lead free electronics is changing the component lead finishes offered by component suppliers. This impacts all electronic equipment manufacturers whether or not they need to produce lead free products. Two considerations when choosing an alternative lead finish are its impact on manufacturing quality and product reliability. Component finishes with acceptable manufacturing quality should have intrinsic solderability with lead based and lead free solders, a reproducible method for its application, and a reproducible method for soldering quality over an economically viable shelf life. A finish with acceptable product reliability is intrinsically stable, has a stable reaction with its neighboring materials and environment, and durable in the use environment. The component finish also must meet the environmental requirements of legislation and be economically viable.

A survey of 72 suppliers responding in the industry found a variety of component finishes being proposed [20]. The survey results are shown in Figure 1. Note that some suppliers offer more than one component finishes so that the total percent added up is more than $100 \%$. Some of the finishes being considering are plated $\mathrm{Sn}, \mathrm{SnBi}, \mathrm{SnCu}$, SnCuAg, and NiPd or NiPdAu. The realistic outlook is that a larger mix of component surface finishes will be represented on a circuit board assembly for 
consumer and commercial products regardless of lead-free requirements. The soldering process for an assembly will need to be compatible with all these finishes and able to produce a reliable solder joint for the finish with the poorest intrinsic solderability.

The most popular choice is by far plated tin (Sn) as evidenced by $51 \%$ suppliers offer it as component finish. This is not surprising since it is a well controlled bath, easily switched from a $\mathrm{SnPb}$, low cost, and has good solderability, but is prone to metal whisker growth as reported by numerous publications such as NASA [21]. Some high reliability applications such as Boeing satellite systems and Raytheon ban pure tin as a component finish.

Plated Tin is followed in popularity by tin bismuth ( $\mathrm{SnBi}$ ) and finishes containing nickel palladium (NiPd or NiPdAu). $\mathrm{SnBi}$ is offered by some component suppliers responding to the survey. It has been found to solder with acceptable workmanship using $\mathrm{SnPb}, \quad \mathrm{SnAg} 3 \mathrm{Cu} 0.5$, SnAg4.0Cu0.5, and SnBiAg in practice [22]. A SnBi bath has a higher producer maintenance cost than a Sn bath due to the high standard electrode potential between $\mathrm{Sn}$ and $\mathrm{Bi}$ causing $\mathrm{Bi}$ to immersion plate onto the anode. Nickel Palladium (NiPd) or Nickel Palladium Gold (NiPdAu) has been offered for many years by Texas Instruments (TI). The solderability is slightly less than the other finishes listed but no reports of solder joint failures have been made when used on copper leadframes. NEMI Tin Whisker Users Group recommends NiPdAu as a whisker free alternative but warns that molding compounds do not adhere as well to noble metals (Pd, $\mathrm{Au}$ ) as they do to $\mathrm{Cu}$ [23].

$\mathrm{SnCu}$ is another component finish. A tin copper $(\mathrm{SnCu})$ bath has a higher maintenance cost than $\mathrm{SnBi}$ due to the even higher standard electrode potential between $\mathrm{Sn}$ and $\mathrm{Cu}$ causing $\mathrm{Cu}$ to immersion plate onto the anode. The immersion plate will form a $\mathrm{Sn}_{5} \mathrm{Cu}_{6}$ intermetallic layer that can degrade solderability. Thickness measurement of $\mathrm{SnCu}$ is also difficult when it is plated on a copper lead frame using conventional methods such as $\mathrm{X}$ Ray Fluorescence (XRF). Other finishes that are also offered by a few suppliers are plated SnAg and lead free solder dipped finishes. Careful control of the SnAg plating process is needed since the melting point of the binary alloy increases rapidly above $5 \%$ silver content. SnAgCu solder dipped leads have been produced with acceptable workmanship in $\mathrm{SnPb}$, SnAg3.0Cu0.5, and SnCu0.7 soldering processes [22]. Solder dipped leads after tin plating has the risk of whisker formation if the solder dipping does not cover all the tin.

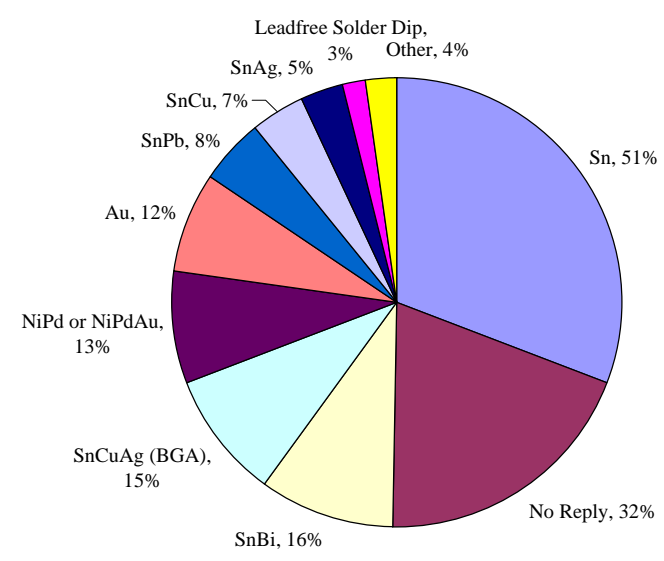

Figure 1 Component Finish Survey

It should be pointed out that the component finishes listed above are not available for every package type. Component manufacturers are undergoing extensive qualification testing for all lead-free finishes. At this time, most package styles only have one or two lead-free finishes available. The common component finish for chip resistors and capacitors is $100 \%$ tin due to its low cost. SnAgCu is by far the choice for Ball Grid Array (BGA) and Chip Scale Package (CSP) components. The popular component finishes for leaded packages such as Quad Flat Package (QFP) and Small Outline Package (SOP) are plated tin, $\mathrm{SnBi}, \mathrm{SnCu}$, and $\mathrm{NiPd}$ or NiPdAu. NiPdAu (or just plain NiPd) is favorable for these leadframe packages due to its whisker free characteristic, especially in fine pitch applications.

There is evidence from published documents that there is variability in the solderability of lead-free component finishes. Reliability of solder connections depends on the integrity of the solder joint and the component finish is an important constituent. The component finish interacts with the solder alloy in a metallurgical reaction to generate a reliable solder joint is indicated by solderability. Component lead finish solderability is a function of preconditioning, temperature, and time. For example, the time a lead is in contact with molten solder in a wave soldering process is on the order of 3 to 5 seconds and 60 to 90 seconds for reflow soldering. Doyle [24] and Fan [25] reported the effects of preconditioning and solder temperature on $\mathrm{SnPb}, \mathrm{Sn}$, and $\mathrm{SnCu}$ finishes. Variability in wetting among the lead finishes, solder temperature, and the time to wet is noted. A slight increase in wetting time is found when using a lead free alloy. Other studies on $\mathrm{Ni} / \mathrm{Pd}$ component finishes show comparable results to $\mathrm{SnPb}$. 


\section{Lead-Free Printed Circuit Board Finishes}

The main function of PCB finishes is to enhance the solderability of the substrate or underlying layer so that reliable solder joints will achieve at the board level assembly. Another important function of PCB finishes is to be wire bondable.

The most common circuit board finish used for $\mathrm{SnPb}$ products is $\mathrm{SnPb}$ Hot Air Solder Leveled (HASL) finish. There have been a number of replacements proposed since the early 1990s with the focus of obtaining flatter pads for fine pitch components and a desire by the printed circuit board fabrication industry to eliminate this high maintenance and difficult to control process. These finishes have also been proposed and evaluated for lead-free finishes. The alternatives include organic solderability preservatives (OSP), gold over nickel (electroplated or Electroless Nickel Immersion Gold (ENIG)), immersion silver, immersion tin, and leadfree HASL. The choice of finish has typically dependent on the process environment (reflow parameters and alloy dependent) and reports for the best performing finish has been varied between testing parties. A rating of circuit board finishes by the members of the NEMI Tin Whisker Users Group members shows this variation. Nine participants rated the risk of the five alternatives (lead-free HASL uses $\mathrm{SnCu}$ ) and the results are reproduced in Table 1. The table is ordered according to preference.

Table 1. NEMI Users Group PCB Finish Rating [23]

\begin{tabular}{|l|c|c|c|c|}
\hline \multicolumn{1}{|c|}{ Finish } & Recommend & Risky & $\begin{array}{c}\text { Not } \\
\text { Acceptable }\end{array}$ & $\begin{array}{c}\text { No } \\
\text { Vote }\end{array}$ \\
\hline Immersion Ag & 6 & 2 & 0 & 1 \\
\hline Immersion Sn & 5 & 3 & 0 & 1 \\
\hline OSP (Entek) & 5 & 2 & 1 & 1 \\
\hline ENIG & 4 & 2 & 2 & 1 \\
\hline HASL (SnCu) & 2 & 4 & 0 & 3 \\
\hline
\end{tabular}

\subsection{Immersion Silver}

Immersion silver is one of the finishes that are reported to be used successfully with lead-free solders. Wetting is good, the finish can withstand multiple reflow passes [26], and it has a good shelf life (6-12 months). The surface is wire bondable. It has originally marketed for its flat surface to be compatible with fine pitch surface mount but is also an option for lead free assemblies. The thickness is about 0.127 microns with an optimum range of 0.08 to 0.16 microns. Thickness less than 0.04 microns will result in poor solderability. Silver is a sacrificial layer and must dissolve into the solder joint. Dissolution rate of silver in $\mathrm{Sn}$ is slow so soldering processes with short dwell times (such as hand soldering and wave soldering) may lead to incomplete dissolution of silver and the solder joint will be to the silver coating rather than the copper surface underneath. This may be tolerated in some cases but on elevated temperature aging and solidstate diffusion, the $\mathrm{Ag}_{3} \mathrm{Sn}$ intermetallic can grow at the interface and the mechanical integrity of the solder joint will depend on the brittle $\mathrm{Ag}_{3} \mathrm{Sn}$ intermetallic compound and underlying copper bond.

\subsection{Immersion Tin}

Immersion tin is a replacement process. Tin in the immersion tin solution replaces copper in the substrate and the copper goes into solution. The thickness is on the order of 0.1 to $1.5 \mu \mathrm{m}$. Over time, the tin will form an intermetallic compound with $\mathrm{Cu}$ at a rate that is dependent on temperature. $\mathrm{Cu}_{6} \mathrm{Sn}_{5}$ and $\mathrm{Cu}_{3} \mathrm{Sn}$ phases can form that reduce the solderability of the surface. Shelf life is estimated to be one year based on storage between 20 and $30^{\circ} \mathrm{C}$ for the thickness noted [27]. Multiple reflow passes with immersion tin is not recommended due to degradation in solderability after one reflow pass [28]

\subsection{ENIG}

Electroless Nickel Immersion Gold (ENIG) is a popular lead free printed circuit board finish because of its good solderability performance with a number of lead free solders and ability to withstand multiple soldering passes. Its solderability was rated high on the alloys tested as part of the NCMS lead free study [29]. However, the most popular lead-free solders, SnAgCu, were not included in the NCMS study. ENIG was reported to have the least amount of solder voids in mixed (lead-free and $\mathrm{SnPb}$ ) and total lead-free area array soldering conditions [30].

One issue with ENIG is called "black pad" or "black nickel". Black pad has given some reservation to its use. Black pad is a phenomenon related to some weak solder joints on ENIG surface finish. After the solder joint interfacial fracture is revealed, the exposed nickel pad is black. Black pad is related to the phosphorous content in the electroless nickel coating bath. High phosphorous content has good corrosion resistance but will induce solder joint embrittlement with the growth of an intermetallic layer through phosphorus enrichment during soldering. Low phosphorous content in the electroless nickel coating has poor corrosion resistance and is attacked by the acidic gold bath, which enriches phosphorus concentration on the surface of the electroless nickel coating. The gold coating dissolves quickly into the solder joint and exposes the poor solderable, phosphor rich nickel surface. Careful monitoring and process control is needed to produce an ENIG quality finish. 


\subsection{OSP}

Organic Solderability Preservatives (OSP) is proving to be a popular lead-free PCB finish. OSP is widely used in Japan as Saeki and Carano [31] reported that OSP has 69\% PCB finish market share in 2001 in Japan and Asia, and expect to remain similar level (about 67\%) in 2006. In the U.S., approximately 26\% of PCB finish produced in 2002 use OSP [32]. But it has been reported that OSP didn't work well with lead-free solders with higher melting points. OSP had a higher number of failures during temperature cycling than compared to immersion Ag and immersion Sn [33]. OSP is not as robust to high temperatures as metal finishes and have a smaller process window. Shear strength tests are found to be comparable to immersion Ag, immersion Sn, and ENIG [34].

\subsection{Lead-Free HASL}

Currently the most popular $\mathrm{Sn} / \mathrm{Pb}$ finish for printed circuit boards is HASL. Much attention has been paid to alternatives to HASL for lead-free solutions. Studies have been reported on using the Castin ${ }^{\circledR}$ (a composition of Sn 93-98\%, Ag 1.5-3.5\%, $\mathrm{Cu} .2-2 \%$, and $\mathrm{Sb} .2-2 \%)$ alloy and $\mathrm{SnCu0.7}$ for leadfree HASL [35, 36]. The studies have shown successful coating of circuits with these alloys. For example, a study that included using SnCu0.7 HASL reported good results that are comparable to $\mathrm{SnPb}$ HASL. The test was part of a study by Nortel on various board and component finishes in a $\mathrm{SnCu} 0.7$ soldering process [37]. The primary issues with HASL are controlling thickness and thermal shock the circuit board experiences during the process. The benefits are that solderability is excellent and shelf life is longer compared to the alternatives. Shelf life of 1-2 years is expected from a HASL coated board where OSP and immersion finishes last less than a year.

\subsection{Solderability of PCB Finishes}

The wetting behaviors of different lead-free solders on various PWB surface finishes vary. Sattiraju, et. al. [18] conducted solder paste spread tests and wetting balance experiments with SnAg3.4Bi4.8, SnAg4.0Cu0.5, SnAg3.5, and SnCu0.7 on Sn, NiAu, Ag, and OSP PCB surface finishes. They concluded that pure $\mathrm{Sn}$ is the best surface finishes for reflow only once, but is not suitable for a process with multiple reflow cycles. OSP has the poorest wetability. They also observed better spreading when a nitrogen atmosphere was used.

A study on five board finishes (HASL, $\mathrm{NiAu}$, immersion Ag, immersion Sn, OSP) on 2512 using the SnAg4.0Cu0.5 solder found that immersion
Ag performed about the same as ENIG and immersion Sn [33]. The components were temperature cycled from -55 to $125^{\circ} \mathrm{C}$ and continuously monitored according to IPC-SM-785. Another comparison of immersion Ag and ENIG in temperature cycling $\left(0\right.$ to $100^{\circ} \mathrm{C}$ ) of 2512 chip resistors using SAC405 found that the immersion Ag boards had a higher mean life (5803 cycles) than ENIG (5100 cycles) [38]. However, this study used interval censoring every 250 cycles and the resistance was checked at room temperature, which may result in longer times to indication of failure.

\section{Tin Whisker Formation}

Components have been commonly provided with terminations (a.k.a leads) that have been typically coated with $\mathrm{SnPb}$ to preserve their solderability in storage and suppress tin whisker growth. Plated Sn and high Sn content alloys have been reported to form tin whiskers that may cause electrical shorting. Tin whiskers are spontaneous filaments that grow from plated tin surfaces. Note that tin whiskers grow from vapor deposited tin surfaces has also been reported [39]. Tin whiskers can carry more than $20 \mathrm{~mA}$ of current with figures as high as $100 \mathrm{~mA}$ reported. The whiskers have grown long enough to cause an electrical short to adjacent conductors or break off to cause shorts across other connections. The root cause of tin whiskers is not fully understood yet and accelerated test factors have not been established at this time. The problem has been confounded by inconsistent test reports regarding mitigation steps.

Industry groups are in the process of understanding tin whiskering. In the United States, NEMI has formed task groups to address modeling, accelerated testing, and a group in the University of Maryland (CALCE) has formed to investigate risk mitigation steps. The Japan Electronics and Information Technology Industries Association (JEITA) and the International Tin Research Institute (ITRI) in Europe are also contributing to tin whisker research. NEMI has recently proposed an acceptance test requirement for user acceptance of tin or high tin content finishes [40]. It requires that mitigation steps be taken by the component supplier, such as fusing, nickel barriers, or annealing, be applied to plated Sn finishes. The test regiment includes ambient storage, temperature/humidity, and temperature cycling. Preconditioning is applied to some test groups to represent soldering processes and one test group is biased at 5V. A control group that is expected to whisker and a reference group (i.e. $\mathrm{SnPb}$ ) are run through the test procedures with the samples. Whiskers must appear on any of the test groups for the test regime to be valid. 
Not all lead free finishes whisker the same. Noble metal finishes do no grow whiskers. A comparison of whisker propensity for several different lead finishes submitted to $60^{\circ} \mathrm{C} / 95 \% \mathrm{RH}$ is listed in Table 2 [41]. Any of the high Sn content finishes have a propensity for producing whiskers. It has been reported that $\mathrm{SnCu}$ grows whiskers more rapidly and longer than Sn but Sn grows a greater quantity. Generally it is accepted that $\mathrm{SnPb}$ does not form whiskers but there have been reports of $\mathrm{SnPb}$ whisker formation [21].

Table 2 Tin Whisker Propensity Rank

\begin{tabular}{|c|c|}
\hline $\begin{array}{c}\text { Ranked By Length } \\
\text { (longer to shorter) }\end{array}$ & $\begin{array}{c}\text { Ranked by Quantity } \\
\text { (most to least) }\end{array}$ \\
\hline SnCu $(120 \mu \mathrm{m})$ & $\mathrm{Sn}$ \\
\hline $\mathrm{Sn}(80 \mu \mathrm{m})$ & $\mathrm{SnCu}$ \\
\hline $\mathrm{SnBi}(50 \mu \mathrm{m})$ & $\mathrm{SnBi}$ \\
\hline $\mathrm{SnPb}(40 \mu \mathrm{m})$ & $\mathrm{SnPb}$ \\
\hline
\end{tabular}

Whisker formation of $\mathrm{SnBi}$ has been reported in a report from Texas Instruments [39]. The whisker lengths are short $(50 \mu \mathrm{m})$, but it is not known whether they would continue to grow at the same rate. The NEMI Tin Whisker Users Group includes $\mathrm{SnBi}$ as a whisker mitigation step in concentrations of 2 to $10 \%$ by weight used with leadfree solders [23]. However, used with $\mathrm{SnPb}$ solder there is a concern about forming the low melting point $\left(96^{\circ} \mathrm{C}\right) \mathrm{SnPbBi}$ ternary phase when $\mathrm{Bi}$ concentration is greater than $5 \%$. It is recommended that $\mathrm{Bi}$ concentration be limited to 3 to $5 \%$ by weight in a $\mathrm{SnBi}$ plated lead.

\section{Reliability of lead free solder joints}

Although SnAgCu alloy is likely to be the replacement of $\mathrm{Sn} / \mathrm{Pb}$ solder, the solder joint reliability database has not been established yet. Tonapi [42] stated that the absence of critical data on the reliability of lead-free solder joint assemblies has become of increasing concern but the available data has been improving since his publication.

Reliability of a solder joint is defined as the probability that the solder joint can perform a required function under given conditions for a given time interval. So reliability is application specific and the reliability of a solder joint depends on the component (including size, packaging type, and component surface finish or metallization), the PCB board finish, the solder paste, solder joint geometry and test conditions. Component sizes and packaging types, and test conditions determine the loading condition on the solder joint. Intermetallic layers formed at the interfaces between the solder and the component metallization, and between the solder and the PCB metallization will affect the mechanical performance of the joint. Because of this, it is inappropriate to say "lead-free solders in general are more reliable than $\mathrm{SnPb}$, or vice-verse.” We should specify the detailed information on components, boards, solders, and testing conditions. In addition, the manufacturing assembly processes would contribute the reliability of the solder joint. For example, reflow profile will influence wetting and microstructure of the solder joint. The reflow profile of $\mathrm{SnPb}$ and $\mathrm{SnAgCu}$ should be different due to different melting temperature. To make the reliability comparison between $\mathrm{SnPb}$ and $\mathrm{SnAgCu}$ solders meaningful, the reflow profile should be optimized for the specific solder alloy.

A solder joint consists of the solder alloy, the component metallization, and the PCB metallization as shown in Figure 2. Failure of a solder joint can occur at the bulk solder or at the interfacial intermetallic layer between the solder and the component or between the solder and the PCB. A solder joint failure could be caused by crack initiation and growth (fatigue failure), or by macroscopic solder facture (facture failure). The crack initiation and growth is generally the result of grain coarsening, grain boundary sliding, or void formation and growth when solder joints experience stress under the reliability tests or service conditions.

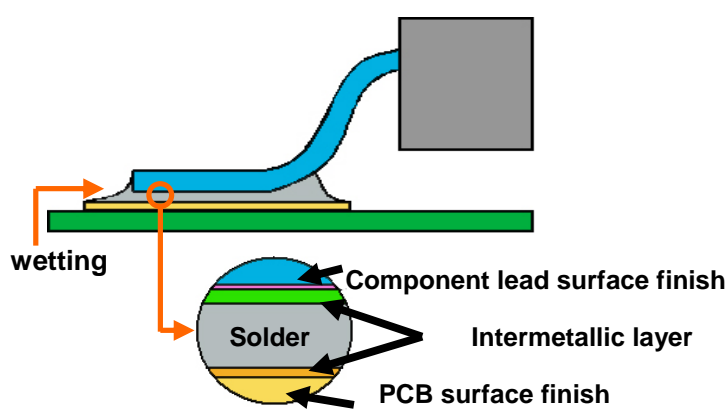

Figure 2. A typical solder joint

Fatigue failure is normally the result of power cycling, temperature cycling, or mechanical vibration. Facture failure commonly results from bending, twisting, mechanical shock, and free fall drop. The most common reliability threat comes from stress-relaxation based (thermal) fatigue damage [43]. Life prediction of a solder joint can be achieved by mathematical modeling and/or experimental testing.

\subsection{Reliability modeling}

The thermal fatigue life of a solder joint is dominated by the joint's creep responses to thermal cycling. The solder joint life can be estimated by the Coffin-Mansion equation as reported by Lau et al. [44]: 


$$
N_{f}=\psi(\Delta W)^{\varphi}
$$

where $N_{f}$ is the number of thermal cycles to failure, $\Delta W$ is the creep strain energy density per cycle, and $\psi$ and $\varphi$ are fatigue crack-growth material constants. Lau et al. [45] further demonstrated that for a given joint structure (geometry), material properties (PCB, IC package, and solder), and thermal loading cycle, the creep strain energy density per cycle, $\Delta W$, can be determined by creep analysis using Finite Element Analysis (FEA) method. While powerful FEA tools are readily available, the constants in the constitutive equations for FEA input have to be obtained from experiments. The material data such as Young's modulus, coefficient of thermal expansion, and normal creep strain rate of a lead-free solder (95.5Sn-3.9Ag-0.6Cu) were obtained by Vianco and Rejent [46] and can be used for FEA. However, the critical fatigue crack-growth constants ( $\psi$ and $\varphi$ in Eq. (1)) for this lead-free solder are not currently available for quantitative reliability predictions.

With the same lead-free Sn-Ag-Cu alloy, wave soldering of light-emitting diode (LED) display assembly was tested and analyzed [47]. In the finite element creep analysis, the LED display on a plated through hole (PTH) PCB was modeled as plane strain condition and the creep strain energy density per thermal cycle, $\Delta W$,was calculated. As the quantity of $\Delta W$ is very small, it was concluded, qualitatively, that the solder joint should be reliable under normal operating conditions. It should be noted that, in these FEA efforts, the thermal expansion mismatch between materials leads to shear stress and creep shear strain. The joints were analyzed based on continuum models without imperfections. Failure mechanisms such as crack initiation and void growth were not specifically addressed.

\subsection{Experimental testing methods}

Experimental evaluation of a solder joint reliability is often through accelerated reliability tests though acceleration factors are not well understood yet. The accelerated reliability tests include power cycling, temperature cycling, thermal shock, mechanical vibration, mechanical shock, bend test, and free fall drop test. Which tests should be performed depends on product requirements and service environmental conditions.

The most common accelerated reliability test is temperature cycling because it simulates thermo-mechanical solder fatigue, which is the key failure mechanism in solder joints. During field service, the solder joints are subjected to thermal- mechanical stresses resulting from the coefficient of thermal expansion (CTE) mismatch between the package and the board caused either by power cycling or environmental temperature changes. Two common temperature cycle profiles used in reliability tests are:

1. Thermal cycling from $-40^{\circ} \mathrm{C}$ to $125^{\circ} \mathrm{C}$ per JEDEC JESD22-A104B (July 2000, Condition G)

2. Thermal cycling from $0^{\circ} \mathrm{C}$ to $100^{\circ} \mathrm{C}$ per IPC9701 Test Condition 1.

How can we determine a solder joint has failed after the accelerated reliability tests? Functions of a solder joint are to provide mechanical interconnection and electrical interconnection. Thus, if the joint is unable to resist enough mechanical load, or the solder joint resistance increases significantly (even electrical open), we say the solder joint fails. Accordingly, there are two solder joint performance evaluation methods. One is to monitor pull strength or shear strength after every certain number of temperature cycles or other reliability tests [48 and 49]. The other is to monitor resistance change after certain number of temperature cycles or other reliability tests [50, 51, and 52]. Few researchers use visual inspection to evaluate the solder joint quality [53]. Visual inspection is highly unreliable and labor intensive. It should be pointed out that the visual inspection specifications for leadfree solder joints should be different from that for $\mathrm{SnPb}$ joints because lead-free solder joints look less shiny comparing with $\mathrm{SnPb}$. IPC is revising the IPC610 standard to revision $\mathrm{D}$ for lead-free workmanship. It is expected to release in November 2004.

Pull test can be used for leadframe packages such as QFP and SOP to evaluate solder joint performance. The pull test is generally performed at a $45^{\circ}$ angle as shown in Figure 3 to create a combination of tensile and shear stress on the solder joint [48 and 49]. Note that the pull strength at the hook is different from the pull strength at the solder joint. The pull strength at the solder joint can be calculated given the geometry of the lead. For chip resistors and BGA packages, shear test rather than pull test is used because there is no lead in these packages to pull. One concern of shear testing on BGA packages is that there may be no significant difference in shear strength between good joints and bad joints if only one or two solder joints cracked or failed and all others are still in good shape.

Resistance monitoring is another popular way to evaluate solder joint performance. Based on IPC-9701, the practical definition of solder joint failure is the interruption of electrical continuity ( $>1000$ ohms) for periods greater than 1 microsecond. 
An event detector (AnaTech or equivalent conforming to IPC-9701) is used to monitor the resistor of each channel and record the time of each potential failure (resistor exceeds the reference threshold resistor value). Generally daisy-chained dummy components and daisy-chained routed PCBs are used in the test. One of daisy-chain patterns for dummy components with $\mathrm{N}$ leads is as follows: lead 1 is connected to lead 2, lead 3 is connected to lead 4, ..., lead $\mathrm{N}-3$ is connected to lead $\mathrm{N}-2$, lead $\mathrm{N}-1$ is connected to lead $\mathrm{N}$. In order to create a electrical continuity, a corresponding daisy-chain pattern for the PCB have connections as follows: pad for lead 2 is connected to pad for lead 3, pad for lead 4 is connected to pad for lead $5, \ldots$, pad for lead N-2 is connected to pad for lead N-1. Test points should be connected to pad for lead 1 and pad for lead N. Note that different companies may offer dummy components with different daisy-chain patterns.

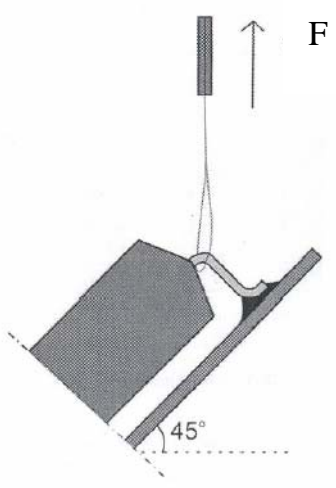

Figure 3. A typical pull test method

To understand how a solder joint fails, the cross-sections of solder joints are commonly characterized by scanning electron microscopy (SEM), or voids or cracks are examined using X-Ray. Through the analytical tools, the microscopic structure of solder joints can be revealed.

\subsection{Experimental Testing Results}

The lead-free solder joint reliability studies have been reported a lot recently although many questions remain. Some researchers reported the reliability of $\mathrm{SnAgCu}$ is equivalent or better than $\mathrm{SnPb}$ in terms of cycles to failure in temperature cycling tests, while others reported vice verse. As discussed before, solder joint reliability is application specific. It not only depends on the component finish, the solder paste, solder joint geometry, and PCB finishes, but also depends on the assembly processes and the testing conditions. It seems that many thermal fatigue experimental data suggested a conclusion: SnAgCu alloys outperform $\mathrm{SnPb}$ at low strain amplitude applications and vice verse at high strain amplitude applications. Researchers at the CALCE consortium did the reliability study and drew the same conclusion as shown in Figure 4 [54].

For chip resistors/capacitors and leadless packages, the applied strain can be approximately (rough first-order) estimated

$$
\gamma=\frac{d \Delta T \Delta \alpha}{h}
$$

where $\gamma$ is applied strain on solder joints, $d$ is the distance to the neutral point (DNP), $\Delta \mathrm{T}$ is the temperature difference, and $\Delta \alpha$ is the CTE difference between the package and PCB substrate. Here assume all the deformation is taken by the solder joint. But for QFP packages, applied strain on solder joints during temperature cycles is generally much lower than calculated by Equation 2 because of the compliance lead shape. Thus Equation 2 cannot apply for QFP packages.

For BGA packages, Equation 2 is not appropriate either. If based on Equation 2, the solder joints at the outer perimeter of a BGA package would experience the maximum strain because of the largest DNP and fail first. However, experiments results from Motorola's PBGA packages found that the solder joints under and proximate to the silicon die perimeter tend to fail first [55]. This is because of the local CTE mismatch between the silicon die and the Bismaleimide Triazine (BT) substrate. BT is a PBGA substrate material. Nonlinear FEA by Lee and Lau [56] confirmed the results. Lau [57] presented stress-strain analysis for various BGA packages.

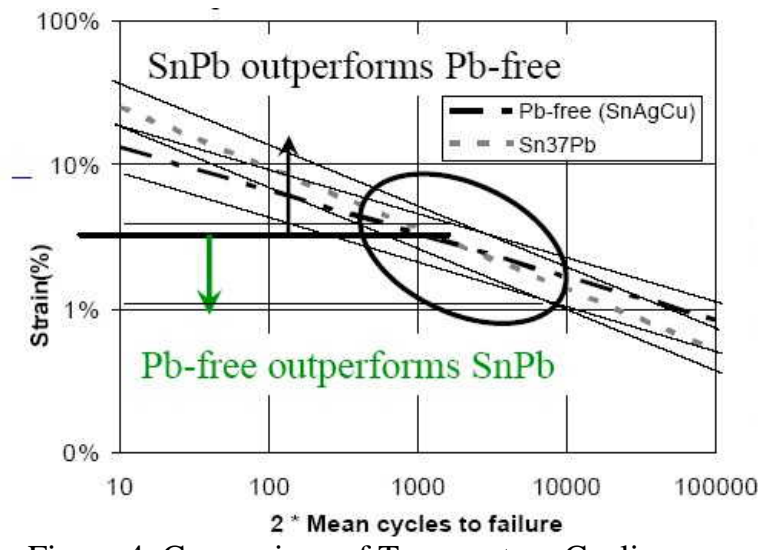

Figure 4. Comparison of Temperature Cycling Mechanical Durability [54]

\subsubsection{Experimental results on leadframe packages:}

Overall, experimental data show that SnAgCu solder joints of QFP packages are as reliable as $\mathrm{SnPb}$. For example, Stam and Davitt [43] reported no failure of solder joints of QFP packages with SnPb15 finish assembled on four board finishes 
(OSP-Cu, Immersion Sn, Immersion Ag, and NiAu) using three solder alloys (SnPb62Ag, SnAg3.8Cu0.7, and SnAgCuX) for up to 5000 power cycles from room to $100^{\circ} \mathrm{C}$. They also reported no pull strength of QFP leads decreased after 5000 cycles. Board level reliability testing on five plating finishes using three different solders is reported by Nakadaira [41]. The plating finishes were $\mathrm{Sn}, \mathrm{SnBi} 2, \mathrm{SnCu0.7}$, $\mathrm{Ni} / \mathrm{Pd} / \mathrm{Au}$, and SnPb15. The solders were SnPb37, SnAg3.5Cu0.7, and SnAg2.5Bi1.0Cu0.5. Four types of packages (LQFP64, PLCC44, QFP100, and PQFP132) were daisy chained and temperature cycled between -40 to $125^{\circ} \mathrm{C}$ using IPC-SM-785 guidance. It was concluded that all the finishes performed comparably with no significant failures before 3500 cycles. Since the strain of solder joints of QFP packages is low, these experimental data agrees with the conclusion: $\mathrm{SnAgCu}$ alloys are as reliable as or better than the $\mathrm{Sn} / \mathrm{Pb}$.

\subsubsection{Experimental results on chip resistors:}

Suhling, et. al. [58] compared thermal cycling reliability of lead-free solder joints of chip resistors 2512. The board finish was ENIG and chip resistor finish was pure $\mathrm{Sn}$. Two temperature cycles profiles ( -40 to $125^{\circ} \mathrm{C}$ and -40 to $150^{\circ} \mathrm{C}$ ) were used and 6,000 cycles each were completed. They found that the reliability of SnAg3.8Cu0.7 and SnPb37 solder alloys were similar at the temperature range from -40 to $125^{\circ} \mathrm{C}$, but SnPb37 outperforms SnAg3.8Cu0.7 at the temperature range from -40 to $150^{\circ} \mathrm{C}$. Based on Equation 2, solder joints have lower strain at the temperature range from -40 to $125^{\circ} \mathrm{C}$ than that the temperature range from -40 to $150^{\circ} \mathrm{C}$. Thus, the result is consistent with the earlier conclusion. Woodrow [4] found $\mathrm{SnPb}$ outperforms SnAgCu in a reliability study of 1206 chip resistors with SnCu0.7 finish. Three board finishes were tested: immersion Ag, NiAu, and OSP. The temperature cycle was from -55 to $125^{\circ} \mathrm{C}$. He also reported that $\mathrm{SnAgCu}$ solder joints were slightly stronger than $\mathrm{SnPb}$ before temperature cycling. Geiger, et. al [59] did cyclic bending tests and shear tests on 0201 resistors with SnPb10 finish. The board finish was ENIG. They compared $\mathrm{SnPb}$ solder and SnAg3.9Cu0.6 solder and found no significant difference to the bending test failures up to 300,000 cycles. They also reported the SnAgCu solder shear strength was about $15 \%$ higher than the $\mathrm{Sn} / \mathrm{Pb}$ solder.

\subsubsection{Experimental results on BGA packages:}

Although Equation 2 is not suitable for calculating the strain of BGA package, generally speaking, Ceramic BGA (CBGA) has larger strain than Plastic BGA (PBGA) because the CTE difference between the CBGA and the FR-4 board is much larger than between the PBGA and the FR-4 board. The strain of BGA solder joints is not only a function of package material, but also a function of package size and standoff height. BGA ball size can have an impact on reliability.

At low strain amplitude application, SnAgCu seems as good as or outperform SnPb. For example, Syed [59] reported SnAgCu showed better performance in reliability than $\mathrm{SnPb}$. He assembled both PBGA and flexXBGA packages on FR-4 board with OSP finish. Temperature cycling was from -55 to $125^{\circ} \mathrm{C}$. Note that flexXBGA uses polyimide tape substrate, which has similar CTE as that of FR-4 board. Lau, et. al. [50] reported there were no solder joint failures on the lead-free balled flexBGA with both $\mathrm{SnAgCu}$ and $\mathrm{SnPb}$ solder pastes on all the Sn$\mathrm{Cu}$ HASL, Ni-Au, and OSP PCBs during temperature cycles from 0 to $100^{\circ} \mathrm{C}$ for 6,000 cycles.

At high strain amplitude application, the reliability of $\mathrm{SnAgCu}$ seems poorer than $\mathrm{SnPb}$. For example, Lau, et. al. [50] reported the test results for the Ceramic Column Grid Array (CCGA) packages with both $\mathrm{SnAgCu}$ and $\mathrm{SnPb}$ solder paste on PCBs with three finishes: Sn-Cu HASL, Ni-Au, and OSP. They found failures on all the three PCBs with $\mathrm{SnAgCu}$, but no failures with $\mathrm{SnPb}$ solder paste.

Though no specific strain value was calculated and compared in published papers, it seems in general that the following conclusion is valid: the reliability of $\mathrm{SnAgCu}$ is similar to or better than $\mathrm{SnPb}$ at low strain amplitude applications and vice verse at high strain amplitude applications. Note that the conclusion is drawn from thermal fatigue modeling and experimental data.

Several researchers noticed that $\mathrm{SnAgCu}$ solder joints have higher pull or shear strength than $\mathrm{SnPb}$ before reliability tests. That is easy to understand because $\mathrm{SnAgCu}$ alloy has higher yield strength than $\mathrm{SnPb}$.

The authors notice that the component metallization and PCB board metallization may not be as critical as solder alloy in fatigue failure mode. But the metallization may be more critical in facture failure mode because it determines the intermetallic characteristic. For example, Arra, et. al. [49] compared mechanical performance of SnAuCu solder joint on QFP208 component with fours finishes $(\mathrm{Ni} / \mathrm{Pd} / \mathrm{Au}, \mathrm{SnPb} 15, \mathrm{SnBi} 2$, and Sn100) under the free fall drop test. The PCB finishes were immersion Ag and OSP. They found the intermetallic layer formed between $\mathrm{Ni} / \mathrm{Pd} / \mathrm{Au}$ finish and $\mathrm{SnAgCu}$ solder was brittle and resulted in failure earlier in the free fall drop test. 


\section{Transition to total lead-free manufacturing}

There are three routes to convert tin-lead soldering to totally lead-free soldering as shown in Figure 5 [60]. Route A is desirable. However, some lead-free finish components may not be available at this time, so companies choose route B. For other companies that allow having lead $(\mathrm{Pb})$ in their electronic equipment by 2010 granted by EU RoHS directive, route $\mathrm{C}$ is applicable.

To switch to lead-free manufacturing, some of surface mount assembly processes needs to be adjusted. Surface mount assembly includes solder paste stencil printing, pick and place, and solder reflow processes. Compared $\mathrm{SnPb}$ soldering with lead-free soldering, there is no significant difference in stencil printing and pick and place processes. The key response variable in the stencil printing process is the solder volume deposited. The stencil printing process is solder paste characterization dependant, not solder alloy dependant. But there are significant differences in solder reflow process. These differences include higher reflow temperature and poorer wetting in lead-free soldering. A new reflow profile with different time and temperature is needed for lead-free soldering. The high reflow temperature may damage sensitive components.

There are many issues in routes $\mathrm{B}$ and $\mathrm{C}$ transition. One of them is the void. More voids have been reported in the solder joints of BGA packages made with $\mathrm{SnAgCu}$ solder balled and $\mathrm{SnPb}$ solder paste [30] and made with $\mathrm{SnPb}$ solder balled and SnAgCu solder paste [61]. How the voids would affect the long-term solder joint reliability is unknown. It is necessary to establish the relationship between the void (including the size of void, the number of voids, and the location of voids) and longterm reliability. Smetana, et. al. [61] summarized other concerns over routes $\mathrm{B}$ and $\mathrm{C}$.

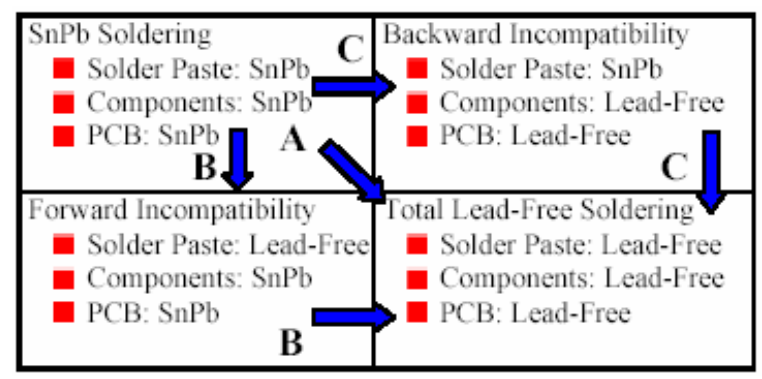

Figure 5. Transition to total lead-free

\section{Summary}

Electronics industry has identified lead-free solder alloy $\mathrm{SnAgCu}$ as possible alternates to eutectic SnPb37 solder, though an agreement on the exact composition has not been achieved.
The common lead-free component finishes include pure $\mathrm{Sn}, \mathrm{SnBi}$, SnCu, NiPdAu, and $\mathrm{SnAgCu}$. At this time, the leading finish available for BGA and CSP packages is $\mathrm{SnAgCu}$, and that for chip resistors is pure tin. Pure $\mathrm{Sn}, \mathrm{SnBi}, \mathrm{SnCu}$, and NiPdAu are available to QFPs and SOPs, and NiPdAu may be favorable for these leadframe packages due to its whisker free characteristic. The leading PCB surface finishes are OSP, ENIG, Immersion Ag, Immersion $\mathrm{Sn}$, and HASL SnCu.

SnAgCu solder joints are generally stronger than $\mathrm{SnPb}$ before reliability tests because $\mathrm{SnAgCu}$ alloy has higher yield strength that $\mathrm{SnPb}$. Reliability of $\mathrm{SnAgCu}$ is application specific. At low strain amplitude application, $\mathrm{SnAgCu}$ seems outperform SnPb. At high strain amplitude application, $\mathrm{SnAgCu}$ performance is poorer than $\mathrm{SnPb}$.

\section{Acknowledgment}

This work was partially sponsored by the Department of the Navy, Office of Naval Research, under Award \# N00014-04-1-0436. The authors would like to thank Dr. John Lau at Agilent, Kim Hyland and Dennis Willie at Solectron, for their valuable comments and suggestions.

\section{References}

[1] Intel webpage http://www.intel.com/research/silicon/leadfree.htm

[2] K. Gaffney, J. Poarch, and D. Delaney, "Leadfree flip chip process development,” Proceedings of 2000 Electronic Components and Technology Conference, IEEE, pp. 129-133.

[3] J. H. Lau and W. Dauksher, "Creep of Sn-(3.53.9)wt\%Ag-(0.5-0.8)wt\%Cu Lead-Free Solder," Micromaterials and Nanomaterials, Edited by B. Michel, Fraunhofer Institute, IZM, Berlin, 2004, pp. 54-62.

[4] T. A. Woodrow, "Reliability and Leachate Testing of Lead-Free Solder Joints," IPC LeadFree Conference, San Jose, CA, May 2002.

[5] National Electronics Manufacturing Initiative (NEMI) webpage http://www.nemi.org/

[6] National Center for Manufacturing Sciences (NCMS) webpage http://www.ncms.org/

[7] High Density Packaging Users Group (HDPUG) webpage http://www.hdpug.org/

[8] Massachusetts Toxics Use Reduction Institute (TURI) webpage http://www.turi.org/

[9] Joint Group on Pollution Prevention (JGPP) webpage http://www.igpp.com/

[10]Computer Aided Life Cycle Engineering (CALCE) webpage http://www.calce.umd.edu/

[11] Tin Technology webpage http://www.tintechnology.com/ 
[12] IPC lead-free webpage http://www.leadfree.org/

[13]K. J. Puttlitz, "Handbook of Lead-Free Solder Technology for Microelectronic Assemblies," Edited by K. J. Puttlitz and K. A. Stalter, Marcel Dekker, Inc., New York, pp. 10, 2004.

[14] T. Siewert, S. Liu, D. R. Smith, and J. C. Madeni, "Database for Solder Properties with Emphasis on New Lead-free Solders,” NIST \& Colorado School of Mines, Release 4.0, Feb. 2002, http://www.boulder.nist.gov/div853/lead free/solders.html

[15] E. Bradley, C. Handwerker, and J. E. Sohn, "NEMI Report: A Single Lead-Free Alloy is Recommended," SMT, January 2003.

[16]S. Denda, "Lower Temp Lead-free Solder Needed,” Advancing Microelectronics, IMAPS, pp. 35, Nov./Dec. 2003.

[17]T. J. Singler, S. J. Meschter, and J. Spalik, "Soldering Wetting and Spreading," Handbook of Lead-Free Solder Technology for Microelectronic Assemblies, Edited by Karl J. Puttlitz and Kathleen A. Stalter, Marcel Dekker, Inc., New York, Chapter 11, pp. 331-429, 2004.

[18] S. V. Sattiraju, et. al., "Wetting Characteristics of Pb-Free Solder Alloys and PWB Finishes,” IEEE Transactions on Electronics Packaging Manufacturing, Vol. 25, No. 3, pp. 168-184, 2002.

[19] J. Bath, “A Manufacturable Lead-Free SurfaceMount Process?” Circuit Assembly, pp. 26-30, January 2003.

[20]CALCE EPSC, Component Suppliers' Survey, Available: $\quad$ http://www.calce.umd.edu/leadfree/tin-whiskers/team/part-suppliers040519.xls, May 19, 2004.

[21] NASA Tin Whisker Website, http://nepp.nasa.gov/whisker/

[22] Experimental results by GE Global Research Center and Solectron.

[23] NEMI Tin Whisker User Group, "Interim Recommendation on Lead-Free Finishes for Components Used in High-Reliability Products”, http://www.nemi.org/projects/ese/tin_whisker_us ergroup.html , March 2004.

[24] C. Doyle, N. Brown, and M. Bardizeh, "Factors Influencing the Solderability of Lead-Free Electrodeposits”, Metal Finishing, January 2002.

[25] C. Fan, Y. Zhong, and J.A. Abys, "Solderability of lead-free finishes using lead-free solders", Proceedings of SMTA International Conference, 9/30/2001, p 827.

[26] M. Arra, “Aging Mechanisms of Immersion Tin and Silver PCB Surface Finishes in Lead-Free Solder Applications”, IPC/JEDEC $3^{\text {rd }}$ International Lead-free Conference, San Jose, CA, March 2003.
[27]D. Ormerod, "Meeting Fine Pitch Assembly Needs with a Solderable Tin Finish", IPC PCB Expo and APEX, March 14-18, 1999.

[28] M. Arra, D. Shangguan, J. Sundelin, T. Lepisto, E. Ristolainen, “Aging Mechanisms of Immersion Tin and Silver PCB Surface Finishes in Lead-Free Solder Applications," IPC/JEDEC 3rd International Lead-free Conference, San Jose, CA, March 2003.

[29] NCMS Lead Free Solder Project Final Report, NCMS Report 0401RE96.

[30] G. Echeverria, D. Santos, P. Chouta, and C. Shea, "Effect of Lead-Free Assembly Processing on Solder Joint Voiding”, IPC-JEDEC $5^{\text {th }}$ International Lead-free Conference, San Jose, CA, March, 2004.

[31]K. Saeki and M. Carano, “Next Generation Organic Solderability Preservatives (OSP) for Lead-Free Soldering and Mixed Metal Finish PWB's and BGA Substrates," IPC Printed Circuits Expo, APEX, and Designers Summit conference, Anaheim, CA, 2004.

[32]R. Schetty, "Lead-Free Finishes for Printed Circuit Boards and Components," Handbook of Lead-Free Solder Technology for Microelectronic Assemblies, Edited by Karl J. Puttlitz and Kathleen A. Stalter, Marcel Dekker, Inc., New York, Chapter 12, pp. 432-464, 2004.

[33] M. Dusek, and C. Hunt, "Reliability Comparison of Lead-free Solder Joints Formed on Different PCB Finishes," IPC/JEDEC $3^{\text {rd }}$ International Lead-free Conference, San Jose, CA, March 2003.

[34]Y. Zheng, C. Hillman, P. McClusky, "Intermetallic Growth on PWBs Soldered with Sn3.8Ag0.7Cu”, Proceedings of the 52nd IEEE Electronic Components \& Technology Conference, pp. 1226-1231, San Diego, 2002.

[35] Teledyne, "No-Lead and Horizontal Hot Air Leveling”, Teledyne document HAL-NoLead004, http://www.tet-halco.com/library.asp

[36] Cemco, "Overview Report on a Lead Free Electronics Industry”, Cemco report, 2001. http://www.cemco.com/Brochures/LeadFreecom plete150301.pdf

[37] K. G. Snowdon, C. G. Tanner, and J. R. Thompson, "Lead Free Soldering Electronic Interconnect: Current Status and Future Developments”, 2000 Electronic Components and Technology Conference, IEEE, p1416-1419.

[38] A.R. Zbrzezny, P. Snugovsky, and D.D. Perovic, "Reliability of Lead-free Chip Resistor Solder Joints Assembled on Boards with Different Finishes Using Different Reflow Cooling Rates”, IPC-JEDEC $5^{\text {th }}$ International Lead-free Conference, San Jose, CA, March, 2004. 
[39]D.W. Romm, D.C. Abbott, S. Grenney, and M. Khan, "Whisker Evaluation of Tin-Plated Logic Component Leads", Texas Instruments Application Report SZZA037A- February 2003; http://focus.ti.com/lit/an/szza037a/szza037a.pdf

[40] Tin Whisker Acceptance Test Requirements, http://www.nemi.org/projects/ese/tin_whisker_us ergroup.html

[41] Y. Nakadaira, et. al., "Pb-free plating for peripheral/leadframe packages," IEEE Proceedings EcoDesign 2001: 2nd International Symposium on Environmentally Conscious Design and Inverse Manufacturing, 2001, pp. 213-218.

[42] S. Tonapi, et. al., "Reliability of Lead-Free Solder Interconnects - A Review,” 2002 Proceedings Annual Reliability and Maintainability Symposium, IEEE, pp. 423-428.

[43] F. A. Stam, and E. Davitt, "Effects of Thermomechanical Cycling on Lead and Lead-Free (SnPb and SnAgCu) Surface Mount Solder Joints,” Microelectronics Reliability, Vol. 41, pp. 1815-1822, 2001.

[44] J. H. Lau, et. al., "Creep Analysis and Thermal Fatigue Life Prediction of the Lead-Free Solder Sealing Ring of a Photonic Switch," ASME Transactions, J. of Electronic Packaging, vol. 124, December 2002, pp. 403-410.

[45] J. H. Lau, D. Shangguan, D. Lau, T. Kung, and R. Lee, "Thermal-Fatigue Life Prediction Equation for Wafer-Level Chip Scale Package (WLCSP) Lead-Free Solder Joints on Lead-Free Printed Circuit Board (PCB)," Proceedings of IEEE Electronic Components and Technology Conferences, Las Vegas, May 2004, pp. 15631569.

[46]P. Vianco, and J. Rejent, “Compression Deformation Response of 95.5Sn-3.9Ag-0.6Cu Solder," UCLA Lead-Free Workshop, October 2002.

[47] J. H. Lau, et. al., "Lead-Free Wave-Soldering and Reliability of Light-Emitting Diode (LED) Display Assembly," IPC First International Conference on Lead-Free Electronic "Towards Implementation of the RoHS Directive", Brussels, Belgium, June 10 - 12, 2003.

[48] H. Tanaka, Y. Aoki, M. Kitagawa, and Y. Saito, "Reliability Testing and Failure Analysis of Lead-Free Solder Joints under ThermoMechanical Stress,” IPC Printed Circuits Expo, $A P E X$, and Designers Summit conference, Anaheim, CA, 2004.

[49] M. Arra, T. Castello, D. Shangguan, and E. Ristolainen, "Characterization of Mechanical Performance of $\mathrm{Sn} / \mathrm{Ag} / \mathrm{Cu}$ Solder Joints with
Different Component Lead Coatings,” SMTA International Conference, 2004.

[50] J. Lau, N. Hoo, R. Horsley, J. Smetana, D. Shangguan, W. Dauksher, D. Love, I. Menis, and B. Sullivan, "Reliability Testing and Data Analysis of Lead-Free Solder Joints for Highdensity Packages,” Soldering \& Surface Mount Technology, Vol. 16, No. 2, pp.46-68, 2004.

[51] S. T. Nurmi, J. J. Sundelin, E.O. Ristolainen, and T. Lepisto, "The influence of multiple reflow cycles on solder joint voids for lead-free PBGAs," Soldering \& Surface Mount Technology, Vol. 15, No. 1, 2003, pp. 31-38.

[52] J.C. Suhling, H.S. Gale, R.W. Johnson, M.N. Islam, T. Shete, P. Lall, M.J. Bozack, J.L. Evans, P. Seto, T. Gupta, and J.R. Thompson, “Thermal Cycling Reliability of Lead-Free Chip Resistor Solder Joints," Soldering \& Surface Mount Technology, Vol. 16, No. 2, pp. 77-87, 2004.

[53] S. Shina, et. al., "Lead Free Conversion Analysis for Multiple PWB/Component Materials and Finishes using Quality and Reliability Testing," IPC Printed Circuits Expo, APEX, and Designers Summit conference, Anaheim, CA, 2004.

[54] "Global Transision to Pb-Free/Green Electronics”, AIA, May 2004. Available at http://www.calce.umd.edu/leadfree/calcePbfree_AIA.pdf

[55] A. Mawer, "Plastic Ball Grid Array (PBGA)," Motorola report AN1231, Phoenix, AZ, 1996.

[56] S. Lee and J. H. Lau, "Effect of Chip Dimension and Substrate Thickness on Plastic Ball Grid Array Solder Joint Reliability," Proceedings of SMI Conference, Sept. 1996.

[57] J. H. Lau and Y. Pao, Solder Joint Reliability of BGA, CSP, Flip Chip, and Fine Pitch SMT Assemblies, Mc-Graw Hill, New York, 1997, Chapter 5.

[58] D. Geiger, F. Mattsson, D. Shangguan, M. Ong, P. Wang, T. Castello, and S. Yi, "Process Characterization of PCB Assembly using 0201 Packages with Lead-Free Solder,” Soldering \& Surface Mount Technology, Vol. 15, No. 2, pp. 22-27, 2003.

[59]A. Syed, "Reliability of Lead-Free Solder Connections for Area-Array Packages," IPC SMEMA Council APEX conference, 2001.

[60] J. Lau and K. Liu, "Global Trends of Lead-Free Soldering,” Advanced Packaging, Jan. 2004.

[61] J. Smetana, R. Horsley, J. Lau, K. Snowdon, D. Shangguan, J. Gleason, I. Memis, D. Love, W. Dauksher, and B. Sullivan, "Design, Materials and Process for Lead-Free Assembly of Highdensity Packages," Soldering \& Surface Mount Technology, Vol. 16, No. 1, pp.53-62, 2004. 